\title{
Excessive ITCZ but Negative SST Biases in the Tropical Pacific Simulated by CMIP5/6 Models: The Role of the Meridional Pattern of SST Bias
}

\author{
SHIJIE ZHOU \\ State Key Laboratory of Numerical Modeling for Atmospheric Sciences and Geophysical Fluid Dynamics, Institute of \\ Atmospheric Physics, Chinese Academy of Sciences, and University of Chinese Academy of Sciences, Beijing, China
}

\section{GANG HUANG}

State Key Laboratory of Numerical Modeling for Atmospheric Sciences and Geophysical Fluid Dynamics, Institute of Atmospheric Physics, Chinese Academy of Sciences, Beijing, and Laboratory for Regional Oceanography and Numerical Modeling, Qingdao National Laboratory for Marine Science and Technology, Qingdao, and Joint Center for Global Change Studies, and University of Chinese Academy of Sciences, Beijing, China

\section{PING HUANG}

State Key Laboratory of Numerical Modeling for Atmospheric Sciences and Geophysical Fluid Dynamics, Institute of Atmospheric Physics, Chinese Academy of Sciences, and Center for Monsoon System Research, Institute of Atmospheric Physics, Chinese Academy of Sciences, and Joint Center for Global Change Studies, Beijing, China

(Manuscript received 13 December 2019, in final form 23 March 2020)

\begin{abstract}
In phases 5 and 6 of the state-of-the-art Coupled Model Intercomparison Project (CMIP5 and CMIP6, respectively) models, there is an apparent excessive rainfall bias with a negative SST bias in the tropical Pacific intertropical convergence zone (ITCZ). The regime of the excessive ITCZ but negative SST bias is inconsistent with the common positive rainfall-SST correlation of climate anomalies over the tropics. Using a twomode model, we decomposed the rainfall bias into two components and found that the surface convergence (SC) bias is the key factor forming the excessive ITCZ bias in the historical runs of 25 CMIP5 models and 23 CMIP6 models. A mixed layer model was further applied to connect the formation of the SC bias with the SST pattern bias. The results suggest that the meridional pattern of the SST bias plays a key role in forming the SC bias. In the CMIP5 and CMIP6 models, the overall negative SST bias has two apparent meridional troughs at around $10^{\circ} \mathrm{S}$ and $10^{\circ} \mathrm{N}$, respectively. The two meridional troughs in the SST bias drive two convergence centers in the SC bias favoring the excessive ITCZ, even though the local SST bias is negative.
\end{abstract}

\section{Introduction}

The strong positive correlation between rainfall and local sea surface temperature (SST) in the tropics is almost a common sense in studying their spatial distribution and interannual variations. Spatially, higher SST in one area relative to other tropical areas can drive higher local rainfall; and temporally, positive SST anomalies can often induce positive local rainfall anomalies (e.g., Bjerknes 1969; Gill and Rasmusson 1983; Graham and Barnett 1987; Liebmann and Hartmann 1982). The positive correlation between rainfall and SST in the tropics is mainly due to the dominant role of SST in the

Corresponding authors: Ping Huang, huangping@mail.iap.ac.cn tropical convective instability (e.g., Sobel et al. 2001; Xie et al. 2010).

However, the state-of-the-art climate models participating in phase 5 of the Coupled Model Intercomparison Project (CMIP5) simulate an apparent rainfall-SST regime characterized by positive rainfall but negative SST biases in the tropical Pacific (Fig. 1; analysis details presented in section 2), which does not follow the common positive rainfall-SST correlation. The positive rainfall biases are symmetrical about the equator, featuring an excessive rainfall bias over the intertropical convergence zone (ITCZ), the South Pacific convergence zone, and the southeastern Pacific (Adam et al. 2018; Lin 2007). In the previous studies, the positive rainfall biases in the southeastern Pacific are well known 
(a) Bias of $\mathrm{Pr}$

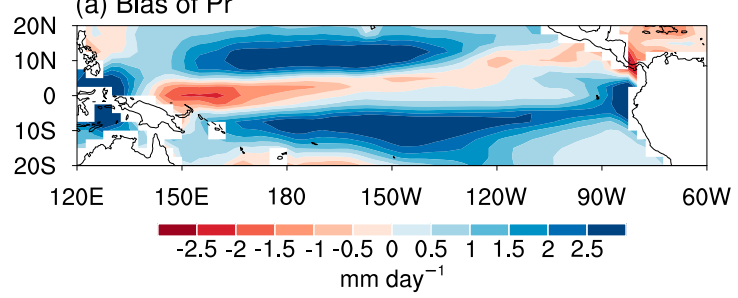

(b) Bias of SST

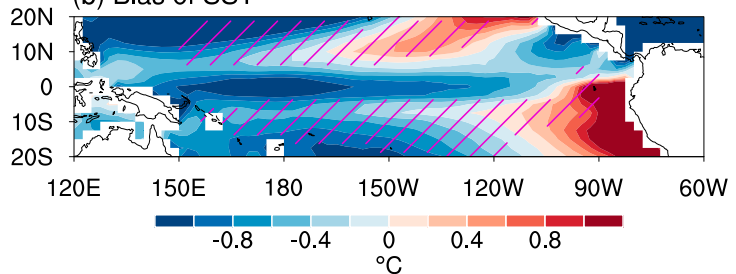

(d) Bias of $\mathrm{Pr}$

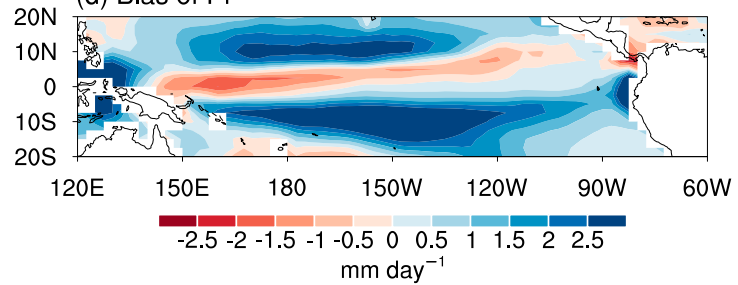

(e) Bias of SST

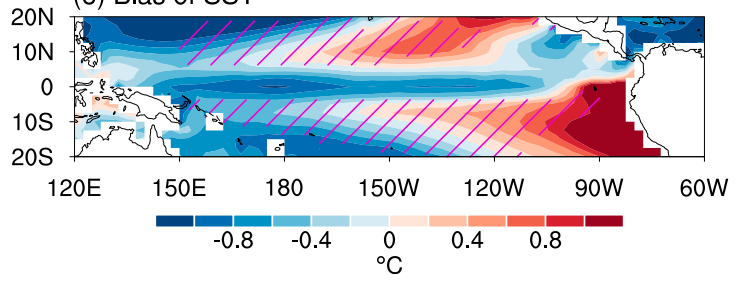

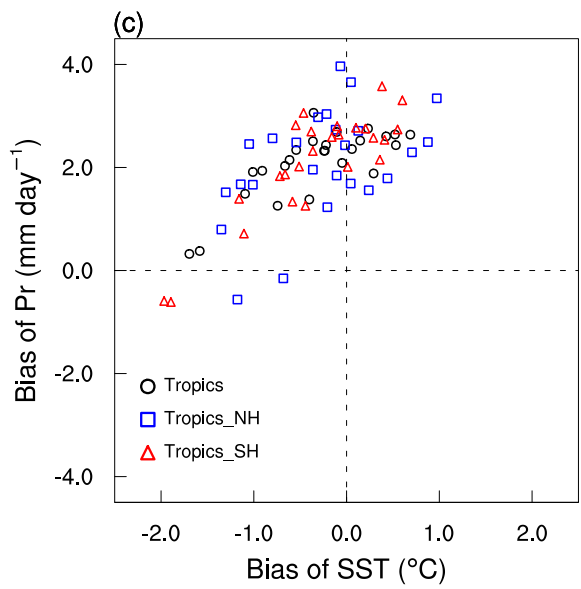

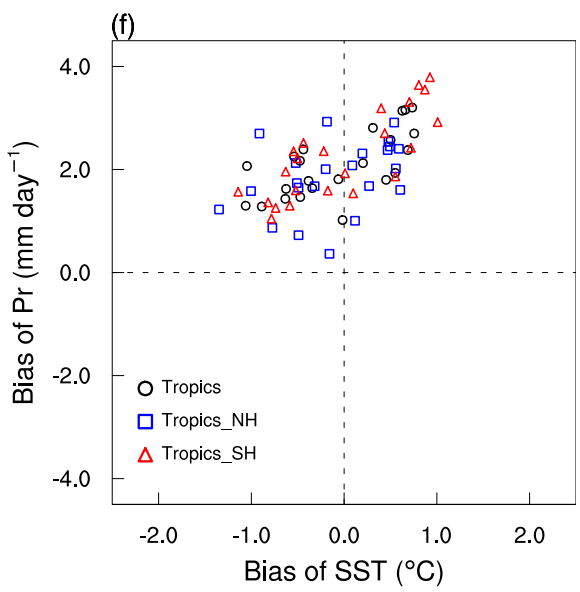

FIG. 1. Annual-mean bias of (a) rainfall and (b) SST in the MME of CMIP5 historical simulations compared with observation. The hatched area in (b) denotes the rainfall bias $\left(20^{\circ} \mathrm{S}-20^{\circ} \mathrm{N}, 150^{\circ} \mathrm{E}-90^{\circ} \mathrm{W}\right)$ greater than $1 \mathrm{~mm}^{-1 a y}{ }^{-1}$ to represent the excessive ITCZ region. (c) Relationship between the area average of SST and rainfall biases (black circles) over the region of the excessive ITCZ bias in the 25 CMIP5 models. The blue squares and red triangles in (c) represent the area average over the Northern and Southern Hemispheres of the excessive ITCZ region, respectively. (d)-(f) As in (a)-(c), respectively, but for CMIP6 models.

as the double-ITCZ problem (Dai 2006; Li et al. 2004; Mechoso et al. 1995). Here, we label the positive rainfall biases over the entire tropical Pacific as the "excessive ITCZ bias" to distinguish from "double-ITCZ bias" term which often refers to the excessive rainfall over the southeastern Pacific.

Many studies have been conducted to understand the double-ITCZ part of the excessive ITCZ problem, and some key factors have been revealed; for example, the convective parameterization scheme (Song and Zhang 2009, 2018; Zhang and Song 2010), the entrainment parameter for the dynamical suppression of deep convection (Hirota et al. 2011; Oueslati and Bellon 2013), the convective mixing rate (Möbis and Stevens 2012), the SST threshold of deep convection (Bellucci et al. 2010), and cross-equatorial energy transport (Hwang and Frierson 2013). The large number of studies indicates the variety of factors contributing to the formation of the double ITCZ (Song and Zhang 2016). For the SST bias in the tropical Pacific, the mechanism of the formation of the cold SST bias in the excessive ITCZ region remains unclear, even though the excessive cold-tongue SST bias and the warm SST bias in the southeastern Pacific bias have been well studied (Fushan et al. 2005; Huang and Ying 2015; Li and Xie 2012; Wittenberg et al. 2006; Yu and Mechoso 1999; Zhang and Song 2010; Zhang et al. 2014; Zheng et al. 2012, 2011).

Previous studies have shown that the biases in models and the intermodel discrepancies with respect to the tropical Pacific rainfall and SST are closely connected to the projected climate changes under global warming (e.g., Huang and Ying 2015; Li et al. 2016; Ying and Huang 
2016). Therefore, the unexplained regime of the excessive ITCZ bias but cold local SST bias will impair the reliability of the climate predictions and future projections given by the models (Samanta et al. 2019; Tian 2015; Wittenberg et al. 2006). Moreover, this rainfall-SST bias regime imposes a barrier to applying the "emergent constraint" approach to correct future climate change projections (Hall et al. 2019), even though some significant emergent relationships have been found.

Actually, besides the direct effect of local SST, the atmospheric surface convergence (SC) is another factor with an important role in tropical rainfall (Back and Bretherton 2009b; Fu et al. 1994; Ramage 1977; Zhang 1993). Based on the combined role of local SST and SC on tropical rainfall, Back and Bretherton (2009b) developed a simple twomode model to explain the climatological pattern of tropical rainfall and connect it to SST and SC. This twomode model can decompose the tropical rainfall-related vertical motion into a shallow mode and a deep mode, which are further related to local SST and SC, respectively. Furthermore, the $\mathrm{SC}$ is closely associated with the gradient of SST, which dominates the gradient of surface air pressure (Back and Bretherton 2009a; Lindzen and Nigam 1987). The two-mode model reveals that tropical rainfall is dependent not only on local SST but also on the SST pattern in a larger region. Recently, the two-mode model decomposition for tropical rainfall was used to understand changes in tropical rainfall and their relationship with the tropical SST change under global warming (Back and Bretherton 2009b; Duffy et al. 2020).

In this study, we use the two-mode model to investigate the formation of the excessive ITCZ but negative SST biases in CMIP5 models and the latest released CMIP6 simulations. The observed and CMIP5- and CMIP6-simulated tropical Pacific rainfall are decomposed into two parts, associated with SST and SC, using the two-mode model. The results show that the meridional pattern of the SST bias in the whole tropical Pacific is another key reason forming the excessive ITCZ bias with negative local SST bias. Section 2 describes the CMIP5 and CMIP6 outputs and observed data used in this study and briefly introduces the two-mode model and mixed layer model. In section 3, we present the results from the two-mode model and emphasize the role of the meridional pattern of SST bias. Conclusions and discussion are presented in section 4 .

\section{Data and methods}

\section{a. Data}

We used the historical runs from 25 CMIP5 models (available at http://pcmdi9.1lnl.gov/; Taylor et al. 2012).
They were ACCESS1.0, ACCESS1.3, BCC_CSM1.1, BNU-ESM, CanESM2, CCSM4, CESM1(BGC), CESM1(CAM5), CMCC-CM, CNRM-CM5, GFDL CM3, GFDL-ESM2G, GFDL-ESM2M, HadGEM2-ES, IPSL-CM5A-LR, IPSL-CM5A-MR, IPSL-CM5B-LR, MIROC5, MIROC-ESM, MIROC-ESM-CHEM, MPIESM-LR, MPI-ESM-MR, MRI-CGCM3, NorESM1-M, and NorESM1-ME (see http://cmip-pcmdi.llnl.gov/cmip5/ availability.html for details). The historical runs from 23 CMIP6 models were also used (Eyring et al. 2016). They were BCC_CSM2-MR; BCC_ESM1; Chinese Academy of Meteorological Sciences Climate System Model, version 1.0 (CAMS-CSM1.0); CanESM5; CESM2; CNRMCM6.1; CNRM-ESM2.1; FGOALS-g3; GISS-E2.1-G; GISS-E2.1-G-CC; GISS-E2.1-H; GFDL CM4; GFDLESM4; HadGEM3-GC31-LL; IPSL-CM6A-LR; MIROCES2L; MIROC6; MRI-ESM2.0; Nanjing University of Information Science and Technology Earth System Model, version 3 (NESM3); Norwegian Climate Prediction Model, version 1 (NorCPM1); NorESM2-LM; Seoul National University Atmosphere Model, version 0, with a Unified Convection Scheme (SAM0-UNICON); and U.K. Earth System Model, version 1.0 (UKESM1.0-LL). The horizontal wind at $1000 \mathrm{hPa}$ was used to represent the surface wind in CMIP datasets. The number of CMIP5 models (25) is arguably quite limited; however, we were restricted by the need for the following analyses to draw upon numerous variables that are unavailable in several of the other models that were not selected. We only selected the first realization (r1i1p1 for CMIP5 and r1i1p1f1 for CMIP6) of each model, excluding CNRM-CM6.1 (r1i1p1f2), CNRM-ESM2.1 (r1i1p1f2), HadGEM3-GC31-LL (r1i1p1f3), MIROC-ES2L(r1i1p1f2), and UKESM1.0-LL (r1i1p1f2) in CMIP6, because of the lack of the first realization in these models.

For contrasting with observational data, we used rainfall data from the Global Precipitation Climatology Project dataset (Adler et al. 2003), SST data from monthly NOAA optimal interpolation SSTs (Reynolds et al. 2002), and surface wind data from scatterometer measurements of sea surface vector wind by the QuikSCAT satellite (Liu et al. 2000). The temperature, geopotential, vertical pressure velocity, and shortwave and longwave radiative fluxes at the surface and top of the atmosphere were obtained from the ERA-Interim dataset (Dee et al. 2011). All the model output and observational data were interpolated onto a $2.5^{\circ} \times 2.5^{\circ}$ grid $\left(90^{\circ} \mathrm{S}-90^{\circ} \mathrm{N}, 0^{\circ}-357.5^{\circ} \mathrm{E}\right)$ using bilinear interpolation before analysis. Although this study focuses on the annual-mean result, all data are monthly and first averaged over years to give climatological monthly values.

The present-day climatology in CMIP5 and CMIP6 is defined as the average from 1981 to 2000 . Since the 
(a) Obs. SST (2000-2008)

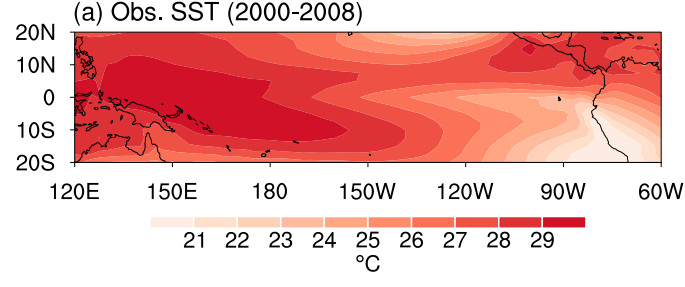

(c) Obs. SST (1981-2000)

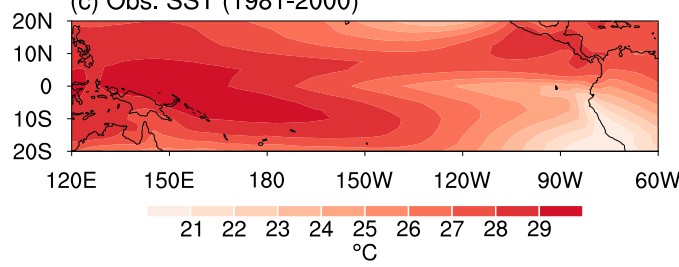

(e) SST (2000-2008) minus SST (1981-2000)
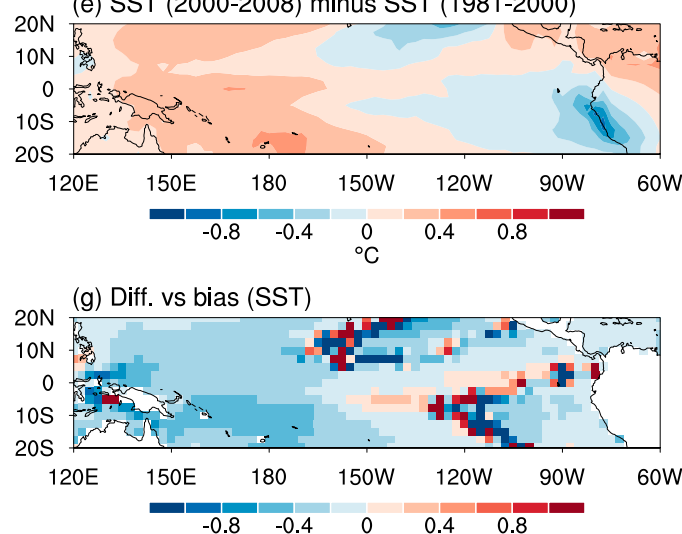

(b) Obs. $\operatorname{Pr}(2000-2008)$

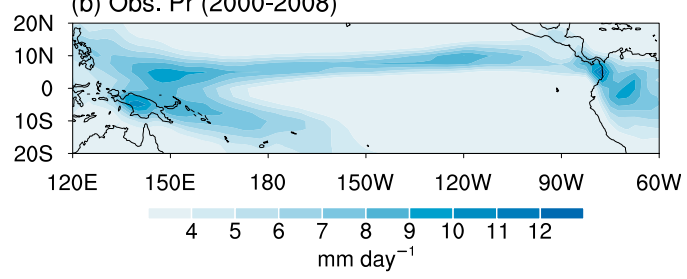

(d) Obs. $\operatorname{Pr}(1981-2000)$

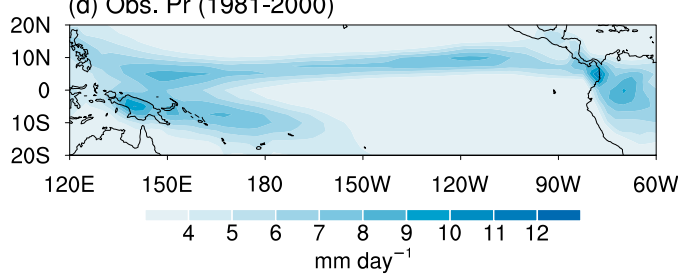

(f) $\operatorname{Pr}(2000-2008)$ minus $\operatorname{Pr}(1981-2000)$

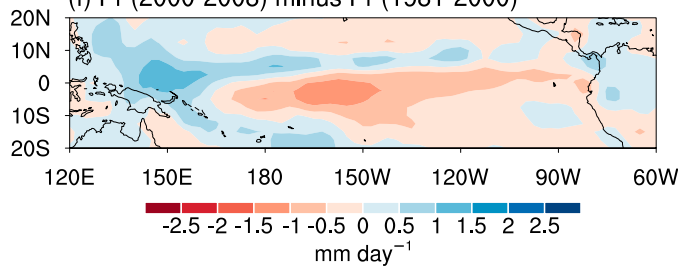

(h) Diff. vs bias (Pr)

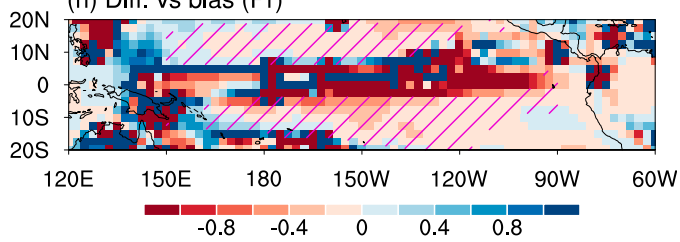

FIG. 2. Annual-mean climatology of observed (a),(c) SST and (b),(d) rainfall in the periods (a),(b) 2000-08 and (c),(d) 1981-2000. The difference in climatology between the periods 2000-08 and 1981-2000 with respect to (e) SST and (f) rainfall. The ratio of the different climatologies of the two periods with respect to (g) SST and (h) rainfall relative to the respective biases in CMIP5 models. The hatched area in (h) denotes the excessive ITCZ region with rainfall bias greater than $1 \mathrm{~mm} \mathrm{day}^{-1}$, as in Fig. $1 \mathrm{~b}$.

surface wind is a very important variable to the twomode model analysis, but reliable wind data from QuikSCAT are only available for the period of 2000-08, the 2000-08 mean was defined as the present-day climatology in observed data. We compared the 1981-2000 mean and the 2000-08 mean in terms of SST and rainfall for the observed data (Fig. 2). The differences of annualmean climatological SST and rainfall between the two periods are shown in Figs. 2e and 2f, respectively. To prove that the differences have little impact on the study of bias, we calculate the ratio of these differences to the SST and rainfall biases in the CMIP5 models (Figs. 2g,h). The impact of the difference between the two periods is little on the SST bias, only a few grids show the values greater than 1 (Fig. $2 \mathrm{~g}$ ). In the excessive ITCZ region [where the annual-mean rainfall bias is greater than $1 \mathrm{~mm} \mathrm{day}^{-1}$ over the tropical Pacific $\left.\left(20^{\circ} \mathrm{S}-20^{\circ} \mathrm{N}, 150^{\circ} \mathrm{E}-90^{\circ} \mathrm{W}\right)\right]$, we found that the difference between the two periods is also negligible compared with the excessive ITCZ biases (Fig. 2h). Therefore, we are confident that the observed climatology defined by the 2000-08 mean does not influence the main conclusions in the present study.

\section{b. Two-mode model}

A two-mode model that depicts the climatological rainfall from SST and SC was used in the present study. This model starts from the dry static energy equation and considers a simplified balance between the adiabatic variation due to vertical motion, radiative cooling and latent heating. The vertical motion is further represented by two modes, the shallow and deep modes, which can together explain more than $90 \%$ of the vertical motion variability in the tropics. The shallow mode is theoretically connected to SC only, while the deep mode is empirically connected to SC and SST. Meanwhile, the radiative cooling is also empirically linked to these two modes. Thus, tropical rainfall can be approximately 
depicted from the adiabatic variation due to the twomode vertical motion and radiative cooling, and further connected to the SC and SST. The tropical rainfall reconstructed by the two-mode model (denoted as $\left.P_{\text {TMM }}\right)$ can depict the observed and modeled rainfall climatology well in the tropics (Back and Bretherton 2009b; Duffy et al. 2020). To distinguish the components related to different physical processes, we recombined the terms in the shallow and deep mode and decomposed tropical rainfall into two components-the first component consisting of the terms related to $\mathrm{SC} P_{\mathrm{SC}}$ and the heating component $P_{\text {Heat }}$ composed of the remaining terms-which are distinct to the two-mode decomposition in previous studies (Back and Bretherton 2009b; Duffy et al. 2020). The $P_{\mathrm{SC}}$ is linearly related with SC, while $P_{\text {Heat }}$ consists of the terms related to relative SST (calculated as the difference between the SST and its average over the tropical oceans) and spatially averaged radiative heating. More details about the twomode model can be found in the appendix.

\section{c. Surface convergence contributed by SST}

Previous studies have shown that SC can be approximately described by the downward momentum mixing from the above free atmosphere and the gradient of surface pressure using a linear mixed layer model (Back and Bretherton 2009a; Stevens et al. 2002). In the linear mixed layer model, the boundary layer winds driven by the gradient of surface pressure make up the dominant component of SC, which can be written as

$$
\begin{gathered}
u=-\frac{f \frac{\partial p_{s}}{\partial y}+\epsilon_{i} \frac{\partial p_{s}}{\partial x}}{\rho_{0}\left(\epsilon_{i}^{2}+f^{2}\right)}, \\
v=\frac{f \frac{\partial p_{s}}{\partial x}-\epsilon_{i} \frac{\partial p_{s}}{\partial y}}{\rho_{0}\left(\epsilon_{i}^{2}+f^{2}\right)},
\end{gathered}
$$

where $u$ and $v$ are boundary layer horizontal winds, $\epsilon_{i}$ is a parameter related to entrainment mixing at the top of the boundary layer and set to $3.5 \times 10^{-5} \mathrm{~s}^{-1}, f$ is the Coriolis parameter, $\rho_{0}$ is a constant reference density $\left(1.255 \mathrm{~kg} \mathrm{~m}^{-3}\right)$, and $p_{s}$ is the surface pressure. Moreover, the contribution of SST to the surface pressure can be estimated as

$$
p_{s-\mathrm{SST}}=\rho_{0} \bar{\Phi}_{850}\left(2-\frac{1}{2} n \mathrm{SST}\right),
$$

where $\Phi_{850}$ is the geopotential at $850 \mathrm{hPa}$ and the overbar denotes the tropical $\left(20^{\circ} \mathrm{S}-20^{\circ} \mathrm{N}\right)$ mean and $n$ is a constant $\left(1 / 288 \mathrm{~K}^{-1}\right)$. Finally, the linear mixed layer model can estimate the contribution of the SST pattern to SC from SST datasets, mathematically connected to the Laplacian of SST (Duffy et al. 2020). Previous studies have shown that the SC estimated by the linear mixed layer model is highly consistent with the SC directly calculated from the observed or modeled surface wind (Back and Bretherton 2009a). Therefore, the linear mixed layer model is a useful tool to illustrate the impact of the SST pattern on SC.

\section{Results}

\section{a. The SST and rainfall biases among the CMIP5 models}

Figures $1 \mathrm{a}$ and $1 \mathrm{~b}$ show the annual-mean rainfall and SST biases in the CMIP5 historical simulations. There is an apparent excessive ITCZ bias in the tropical Pacific and an associated negative SST bias. We further defined the area where the rainfall bias is greater than $1 \mathrm{~mm}$ day $^{-1}$ over the tropical Pacific $\left(20^{\circ} \mathrm{S}-20^{\circ} \mathrm{N}\right.$, $150^{\circ} \mathrm{E}-90^{\circ} \mathrm{W}$ ) as the excessive ITCZ region to clearly show the relationship between the SST and rainfall biases in each model. The area average of rainfall versus SST biases over the excessive ITCZ region for each model is shown in Fig. 1c. In most CMIP5 models, there is a positive rainfall bias corresponding to a negative SST bias in either the northern part (blue squares in Fig. 1c) or the southern part (red triangles in Fig. 1c) of the excessive ITCZ region. There is an obvious positive intermodel relationship between the excessive ITCZ bias and negative SST bias among the CMIP5 model in Fig. 1c, which cannot change the fact that most points exist in the second quadrant. The results from the CMIP6 models (Figs. 1d-f) are nearly the same as those based on the CMIP5 models. Although the warm SST bias in the southeastern Pacific extends more westward in CMIP6 than CMIP5 (Fig. 1e), this discrepancy does not influence the regime of the rainfall and SST biases (Fig. 1f). From Fig. 1, we can clearly see that the well-known double-ITCZ bias is not only located over the southeastern Pacific but can also extend to the southwestern Pacific, and there is a corresponding excessive rainfall bias in the Northern Hemisphere. Therefore, the double-ITCZ bias could be considered as a part of the excessive ITCZ bias.

\section{b. Rainfall biases presented by the two-mode model}

The two-mode model was used to reconstruct tropical Pacific rainfall and decompose it into the heating and SC components. Figure 3 shows the tropical Pacific rainfall reconstructed by the two-mode model $\left(P_{\mathrm{TMM}}\right)$ in the observations (Fig. 3a) and in the multimodel ensemble (MME) of the CMIP5 historical runs (Fig. 3b). The rootmean-square error (RMSE) of the reconstructed $P_{\mathrm{TMM}}$ 

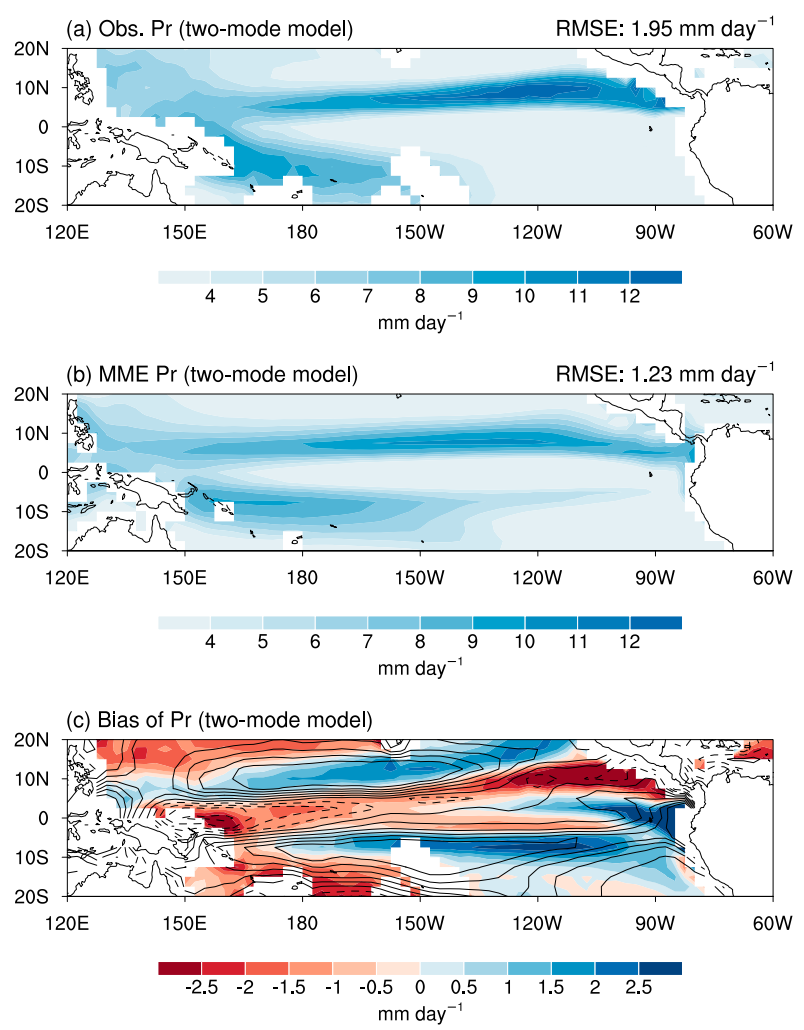

FIG. 3. Reconstructed rainfall $P_{\text {TMM }}$ based on the two-mode model in (a) observations and (b) the MME of the historical runs from 25 CMIP5 models. (c) The bias of the CMIP5 historical $P_{\mathrm{TMM}}$ relative to the observed $P_{\text {TMM }}$. The contours in (c) are the original rainfall bias presented in Fig. 1a (interval: $0.5 \mathrm{~mm} \mathrm{day}^{-1}$ ).

compared to the original rainfall over the tropical oceans $\left(20^{\circ} \mathrm{S}-20^{\circ} \mathrm{N}\right)$ is 1.95 and $1.23 \mathrm{~mm} \mathrm{day}^{-1}$ for the observation (Fig. 3a) and CMIP5 (Fig. 3b), respectively. This result suggests that the two-mode model can successfully capture the pattern and amplitude of the annual-mean tropical Pacific rainfall in the observation and the CMIP5 simulations. The bias of $P_{\text {TMM }}$ in the MME of CMIP5 models relative to the observed $P_{\mathrm{TMM}}$ shown in Fig. $3 c$ resembles the excessive ITCZ bias, characterized by deficient equatorial rainfall and excessive rainfall flanked on both sides of the equator.

The heating and SC components $\left(P_{\text {Heat }}\right.$ and $\left.P_{\mathrm{SC}}\right)$ in the two-mode model are shown in Fig. 4. The pattern of $P_{\text {Heat }}$ (Figs. 4a,b) is closely correlated to the pattern of SST, reflecting the direct heating role of local SST in tropical rainfall. Compared to $P_{\text {Heat }}, P_{\mathrm{SC}}$ (Figs. $4 \mathrm{~d}, \mathrm{e}$ ) exhibits a pronounced variation pattern, similar to the pattern of total rainfall but with apparent negative values. Here, the differences of $P_{\text {Heat }}$ and $P_{\mathrm{SC}}$ between the CMIP5 simulation and the observation define their biases. As shown in Figs. 4c, 4f, 3c, and 1a, the bias of $P_{\text {SC }}$ dominates the total rainfall bias, suggesting the important role of SC bias in forming the excessive ITCZ bias. The bias of $P_{\text {Heat }}$ is mainly contributed by relative SST (not shown), with one order of magnitude less than $P_{\mathrm{SC}}$.

\section{c. Role of the meridional pattern of SST bias}

A linear mixed layer model (see section 2c) is used to investigate the causes of SC bias over the tropical Pacific. Figure 5 shows the $\mathrm{SC}$ estimated from the mixed layer model (SC_mlm) and compares it with the SC directly calculated from the surface wind in the observation and CMIP5 historical simulations. The discrepancies between the direct SC and the estimated SC from the mixed layer model indicate that the mixed layer model underestimates SC, especially in the observation (Figs. 5e,f). Nonetheless, the SC bias from the mixed layer model (Fig. 6b) closely resembles the bias of the direct SC over the excessive ITCZ region (Fig. 6a). Despite the apparent limitations of the mixed layer model over the eastern Pacific, the SC bias from the mixed layer model still provides valuable information. Moreover, the SC biases in both the direct calculation and the mixed layer model estimation are similar to the SC component of the rainfall bias over the excessive ITCZ region (Fig. 4f). Thus, the mixed layer model is a reliable tool for investigating the formation of the rainfall and SC bias and their relationship with the SST pattern bias in CMIP5 simulations.

According to Eqs. (1)-(3), the SC estimated by the mixed layer model is determined by the Laplacian of SST $\left(\partial^{2} \mathrm{SST} / \partial x^{2}+\partial^{2} \mathrm{SST} / \partial y^{2}\right)$, and then the SC bias by the Laplacian of the SST bias (Duffy et al. 2020; Lindzen and Nigam 1987). Since the meridional gradient of the SST bias is much more apparent than the zonal gradient (Fig. 1b), the first term in the Laplacian of the SST bias is much smaller than the second term $\partial^{2} \mathrm{SST} / \partial y^{2}$. The bias of $\partial^{2} \mathrm{SST} / \partial y^{2}$ (Fig. 6c) shows a similar pattern to the SC bias in the direct calculation and the mixed layer model estimation (Figs. 6a,b), suggesting the dominant role of the meridional pattern of the SST bias in the SC bias and in the associated rainfall bias. In the overall negative SST bias simulated by CMIP5 models (Fig. 1b), there are three meridional peaks, at the equator, around $20^{\circ} \mathrm{S}$, and $20^{\circ} \mathrm{N}$, respectively, and two meridional troughs, at around $10^{\circ} \mathrm{S}$ and $10^{\circ} \mathrm{N}$, respectively. The two meridional troughs of the negative SST bias form two convergence centers in SC (negative SC in Figs. 6a and 6b), favoring a positive rainfall bias, in spite of the negative local SST bias. Incidentally, the SST pattern-induced SC bias also plays an important role in the negative rainfall bias at the equator, because of the meridional peak of negative SST bias at the equator. This result suggests that the SC process could be more important for the 
(a) Obs. Pr_Heat

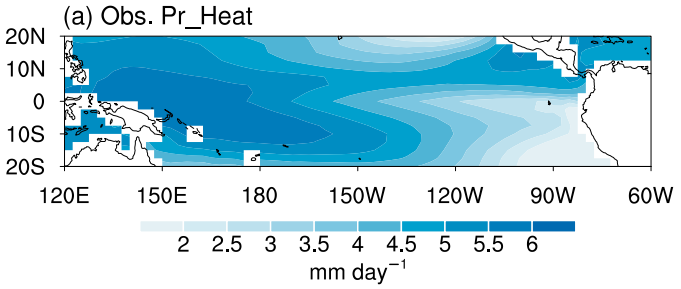

(b) MME Pr_Heat

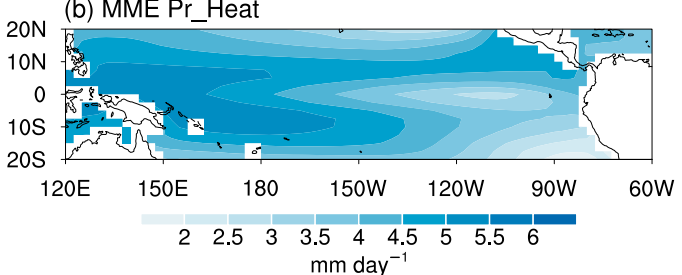

(c) Bias of Pr_Heat

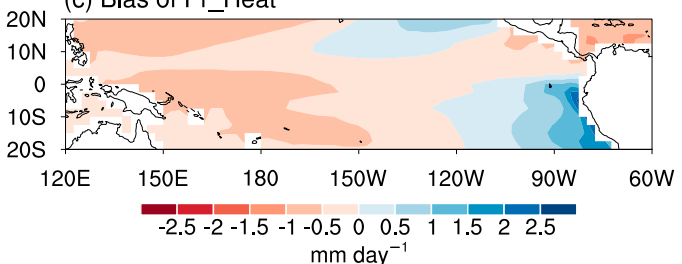

(d) Obs. Pr_SC

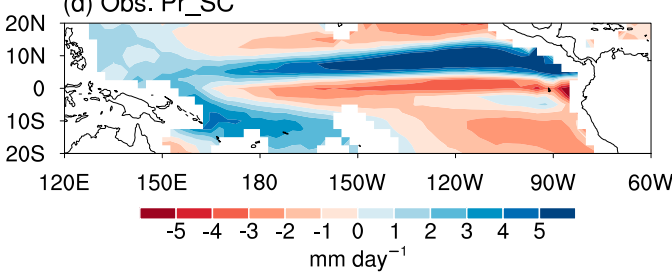

(e) MME Pr_SC

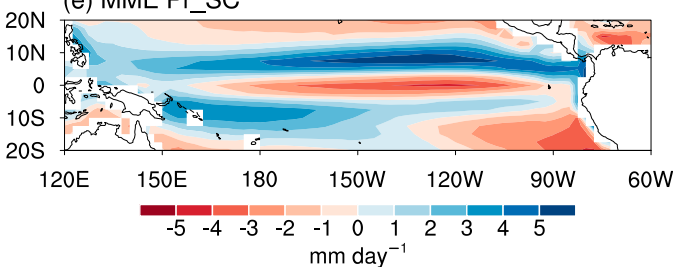

(f) Bias of Pr_SC

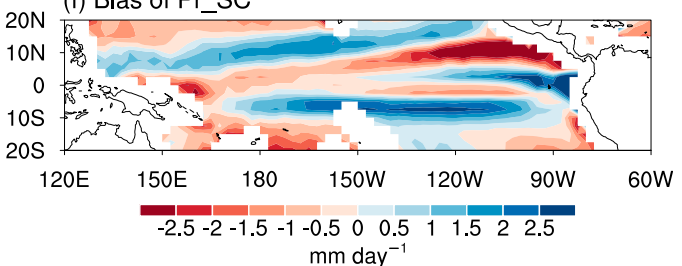

FIG. 4. The (a),(b) heating $\left(P_{\text {Heat }}\right)$ and (d),(e) SC $\left(P_{\text {SC }}\right)$ components of rainfall decomposed by the two-mode model in (a),(d) observations and (b),(e) the CMIP5 models, along with (c),(f) their biases.

excessive cold-tongue bias forming the equatorial deficit of rainfall than direct heating. The same analyses in CMIP6 show that the excessive ITCZ bias is still dominated by the SC bias (Figs. 6d,e), which is then contributed by the meridional pattern of the SST bias (Fig. 6f).

(a) Obs. SC

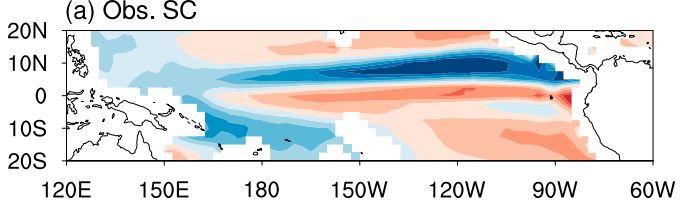

(c) Obs. SC $\mathrm{mlm}$

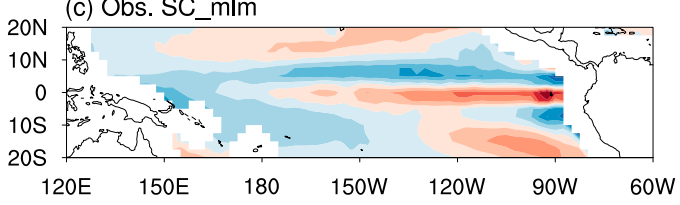

(e) SC - SC_mlm (obs.)

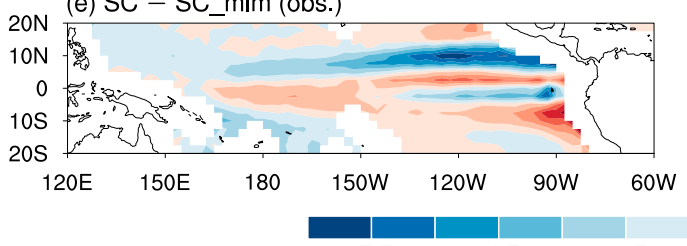

$\begin{array}{lllll}-7.5 & -6 & -4.5 & -3 & -1.5\end{array}$

$$
10^{-6} \mathrm{~s}^{-1}
$$

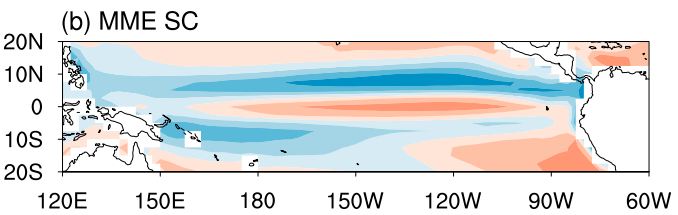

(d) MME SC_m $\mathrm{m} / \mathrm{m}$

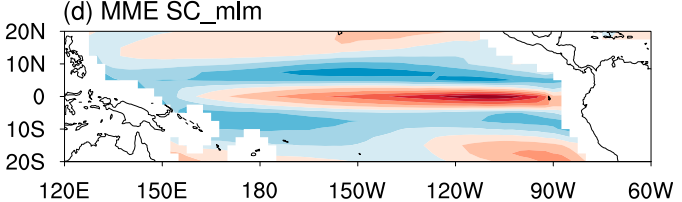

$20 \mathrm{~N}$ (f) SC - SC_mlm (MME)

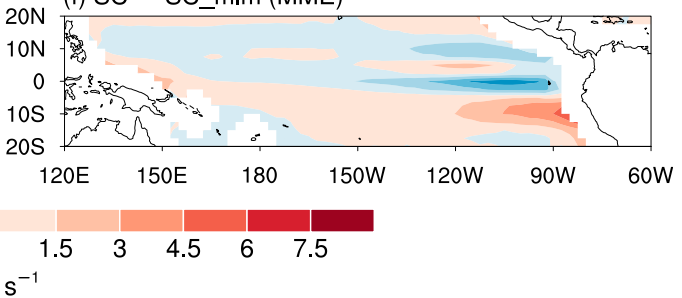

FIG. 5. The SC directly calculated from the (a) observed and (b) modeled surface winds, along with that estimated from the mixed layer model based on the (c) observed and (d) modeled SSTs. The residual of the estimated SC from the mixed layer model relative to the direct calculation in the (e) observations and (f) models. 

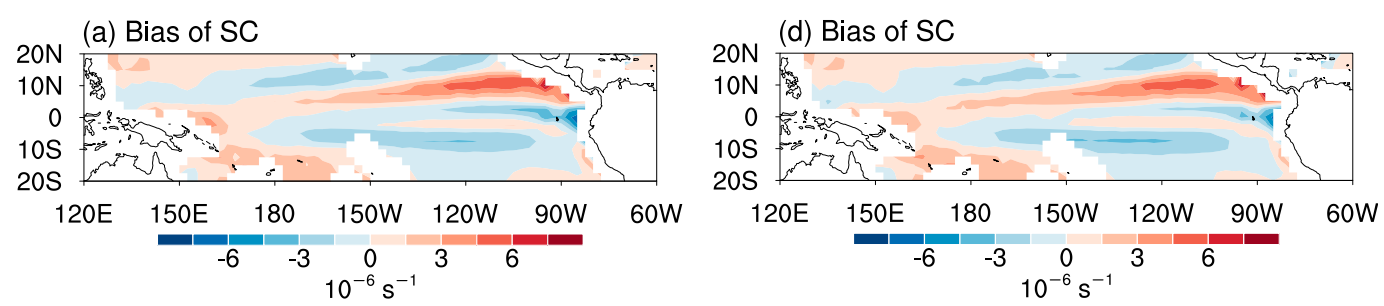

(b) Bias of $\mathrm{SC}$ mlm

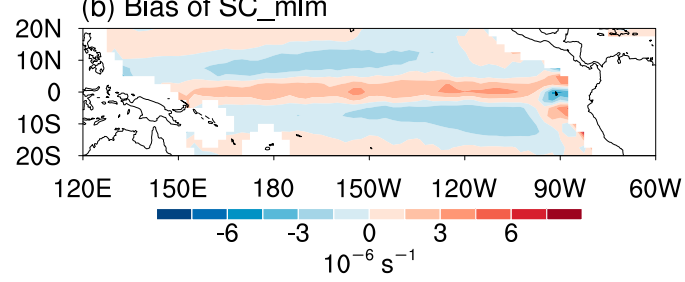

(e) Bias of SC_mlm

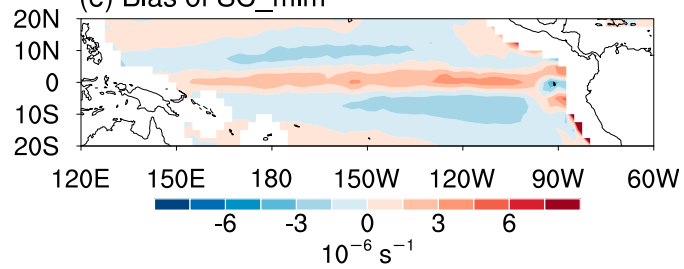

(c) Bias of $\partial^{2} S S T / \partial y^{2}$
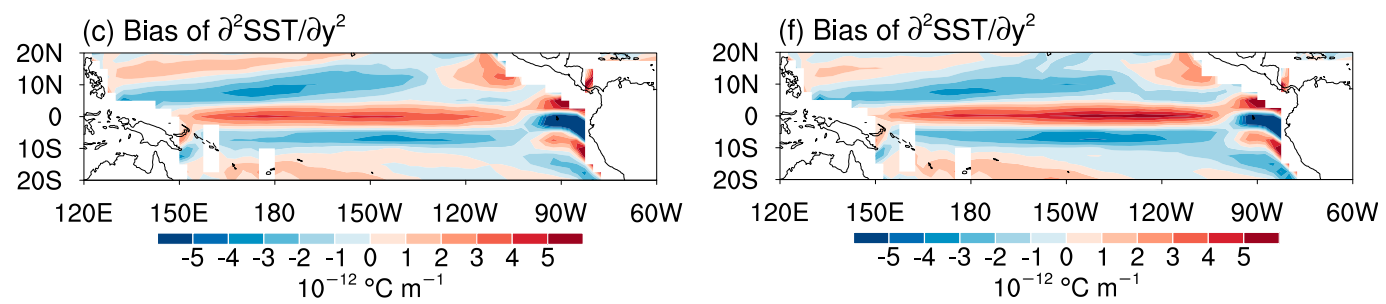

FIG. 6. The SC bias in (a) the direct calculation and (b) the mixed layer model estimation. (c) The meridional term of the Laplacian of the SST bias. (d)-(f) As in (a)-(c), respectively, but for the CMIP6 models.

positive values, similar to the positive bias of the original rainfall in Fig. 1c, corresponding to the negative SST bias. The $P_{\text {Heat }}$ (blue squares in Fig. 7a) is much smaller than the corresponding $P_{\mathrm{SC}}$ (red triangles in Fig. 7a) in most models and shows an inapparent relationship with the SST bias. The relationship between the biases of $P_{\mathrm{SC}}$ and SST is similar with the original rainfall-SST bias relationship in Fig. 1c. However, when the abscissa is changed to the opposite meridional term of the Laplacian of the SST bias, in almost all of the CMIP5 models the excessive ITCZ bias and $P_{\mathrm{SC}}$ are linked to a negative meridional term of the Laplacian of the SST bias (Fig. 7b), consistent with the MME results in Figs. 3 and 6. Also, the same relationships exist in all 23 of the CMIP6 models (Figs. 7c,d). In conclusion, the SC bias driven by the meridional gradient of the SST bias plays a key role in the formation of excessive ITCZ bias over the negative SST biases.

\section{Conclusions and discussion}

In this study, we investigated the formation of the excessive ITCZ bias over the negative SST bias in the tropical Pacific simulated by 25 state-of-the-art CMIP5 models and 23 of the latest-released CMIP6 models. The results suggest that the excessive ITCZ bias is a common bias in CMIP5 and CMIP6, as a larger system bias containing the previously well-known double-ITCZ bias in the southeastern Pacific.

A two-mode model (Back and Bretherton 2009b; Duffy et al. 2020) was used to decompose the tropical rainfall bias into two parts - the surface convergence (SC) component related to SC, and the heating component related to average heating and relative SST - and the excessive ITCZ bias was found to be dominated by the SC component. The SC-component-associated SC bias shows an apparent convergence bias in the excessive ITCZ region. Furthermore, a mixed layer model (Back and Bretherton 2009a; Stevens et al. 2002) was used to investigate the formation of the SC bias and the role of the SST pattern. The results showed that the meridional pattern of the SST bias is the dominant factor of the SC bias. In the overall negative SST bias in CMIP5 and CMIP6, there are two apparent meridional troughs at around $10^{\circ} \mathrm{S}$ and $10^{\circ} \mathrm{N}$, respectively. The two meridional troughs in the SST bias form two convergence centers in SC favoring the excessive ITCZ, even though the local SST bias is negative. The role of the meridional pattern of the SST bias in forming the excessive ITCZ revealed here is consistent with the conclusion in a recent study (Woelfle et al. 2019) emphasizing the meridional pattern of southeastern Pacific SST bias in the doubleITCZ problem. The latest release of the CMIP6 models offers little improvement with respect to the excessive ITCZ bias and its relationship with the SST pattern 

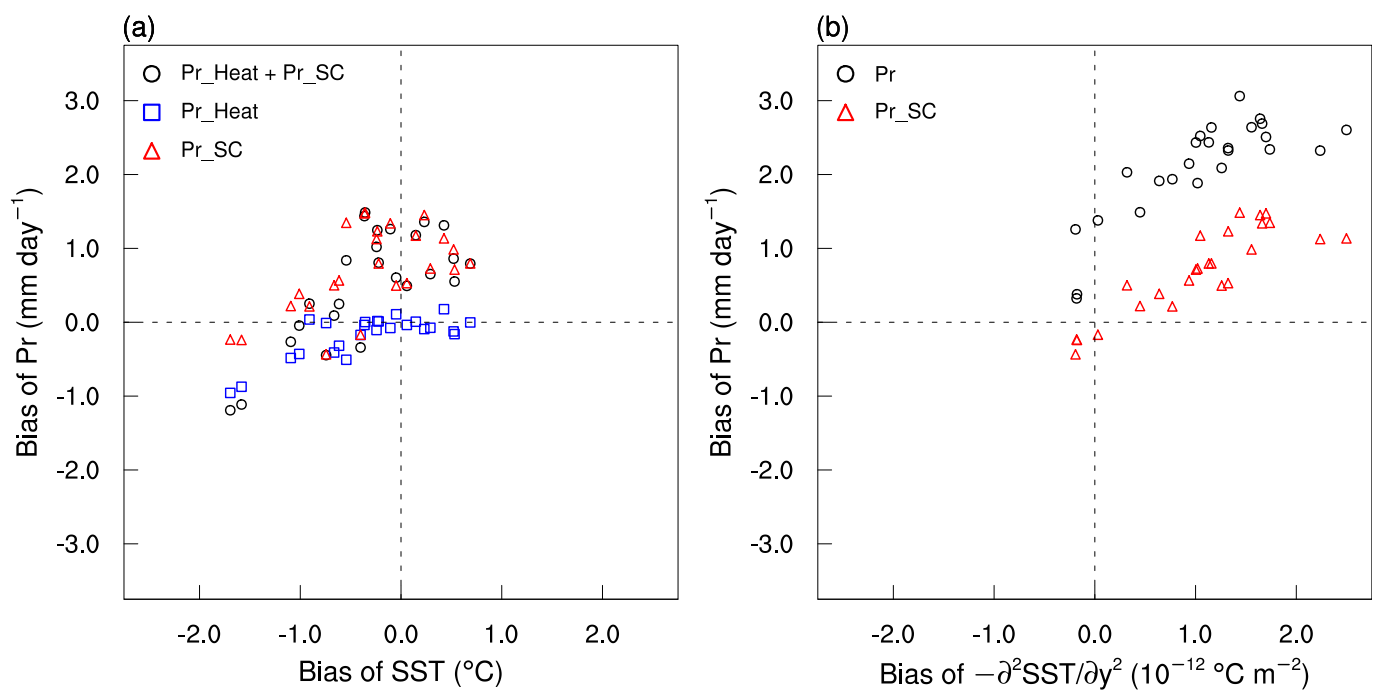

(c)
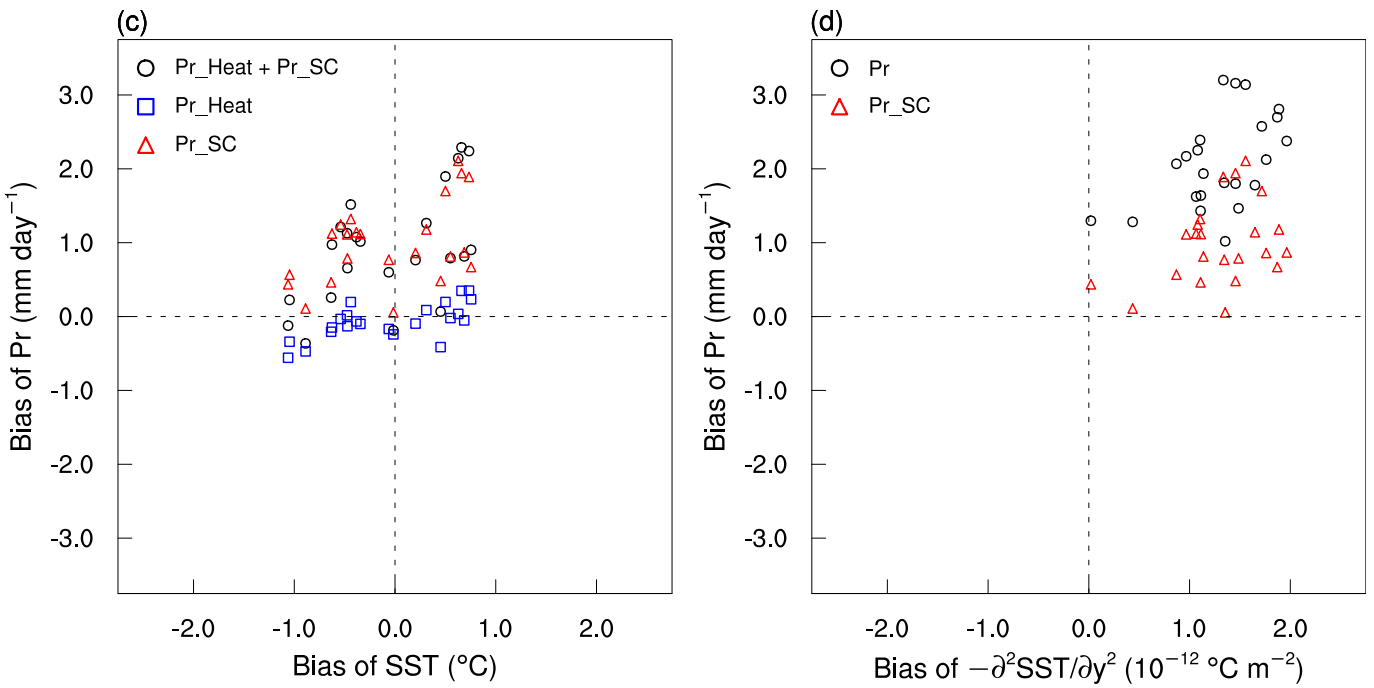

FIG. 7. (a) Relationship between the biases of SST and the reconstructed rainfall in the two-mode model $\left(P_{\mathrm{TMM}}\right.$, $\left.P_{\mathrm{SC}}, P_{\text {Heat }}\right)$ over the excessive ITCZ region in the 25 CMIP5 models. (b) Relationship between the meridional term of the Laplacian of the SST bias and the original rainfall bias and $P_{\mathrm{SC}}$ bias. (c),(d) As in (a) and (b), respectively, but or the CMIP6 models.

bias. This result implies that the meridional structure of tropical Pacific SST is another important factor to simulate realistic tropical Pacific rainfall in climate models.

Although the present study has demonstrated the pronounced role played by the SST pattern bias in the excessive ITCZ bias, the formation of SST pattern bias and how the excessive ITCZ bias could then feed back to the SST pattern bias was not investigated. The sharp meridional SST gradients could be caused by equatorial upwelling. In the tropics, excessive rainfall will decrease the shortwave radiation, thus favoring a negative SST bias. Moreover, the strength of the radiation feedback of rainfall to SST also depends on the climatological convective activity, which further forms a nonuniform SST bias. This rainfall-SST coupled bias and its upper origin are worthy of further study in the future.

Due to the limitation of the two-mode model and the mixed layer model used in the present study, the results on the role of the SST pattern bias can only explain the main part of the excessive ITCZ bias. For example, the two-mode model decomposition for the rainfall bias cannot describe well the positive rainfall bias in the northwestern and southwestern Pacific at around $20^{\circ} \mathrm{S}$ and $20^{\circ} \mathrm{N}$ (Fig. 3c), and the mixed layer model cannot describe well the structure of the SC bias in the northeastern Pacific (Figs. 6a,b). Therefore, more research effort is needed to improve our understanding of the multifaceted processes of the excessive ITCZ bias 
related to deep convection and tropical rainfall from shallow clouds.

Acknowledgments. This work was supported by the National Key R\&D Program of China (Grant 2019YFA0606703), the Key Deployment Project of Centre for Ocean Mega-Research of Science, Chinese Academy of Science (COMS2019QXX), the National Natural Science Foundation of China (Grants 41975116, 41722504, 41831175, 91937302, and 41721004), the Youth Innovation Promotion Association CAS (2016074), and the Fundamental Research Funds for the Central Universities. We acknowledge the World Climate Research Programme's Working Group on Coupled Modeling, which is responsible for CMIP5 and CMIP6, and the climate modeling groups for producing and making available their model output. We thank the two anonymous reviewers for their valuable comments that helped to improve the manuscript.

\section{APPENDIX}

\section{Two-Mode Model}

We apply a simple two-mode model that depicts the climatological rainfall from SST and SC in our study (Duffy et al. 2020). The two-mode model is based on the dry static energy (DSE) budget, relating rainfall to radiative cooling, mean temperature (affecting the DSE stratification), column moist stability, and SC driven by SST gradients. Because our study focuses on tropical rainfall over the Pacific, the eddy DSE fluxes and surface sensible heat fluxes are negligible as in Duffy et al. (2020), the time-mean column-integrated DSE budget is expressed as

$$
L P \cong \frac{1}{g} \int_{p_{t}}^{p_{s}} \omega \frac{\partial s}{\partial p} d p-R
$$

where $P$ is rainfall, $L$ is the latent heat of condensation, $g$ is the gravitational acceleration, $p_{s}$ is the surface pressure, $p_{t}$ is the tropopause pressure $(100 \mathrm{hPa}$ in this study), $\omega$ is the vertical pressure velocity, $s$ is the DSE, and $R$ is the radiative flux convergence between the surface and $100 \mathrm{hPa}$. The DSE is defined as $s=c_{p} T+g z$, where $c_{p}$ is the specific heat capacity of air at constant pressure, $T$ is absolute temperature, and $z$ is height. The radiative flux convergence $R$ is defined as the net shortwave and longwave fluxes at the surface minus the top of atmosphere. Upward radiative fluxes are defined as positive. Although this study focuses on the annualmean result, all data are monthly and first averaged over years to give climatologically monthly value.
We apply an EOF analysis to the climatological monthly $\omega$ with the seasonal cycle over the tropical oceans $\left(20^{\circ} \mathrm{S}-20^{\circ} \mathrm{N}\right)$ and get an approximation of $\omega$ estimated by the two leading EOFs, which are further used to define the shallow and deep modes. The shallow and deep modes are linear combinations of the two leading EOFs. The deep mode is required to have zero SC so that we assume that $\omega$ are equal in the two lowest pressure levels. The shallow mode is defined to be orthogonal to the deep mode. Then we can get $\Omega_{d}$ and $\Omega_{s}$, which are the structures of deep mode and shallow mode, respectively. We can project $\omega$ onto $\Omega_{d}$ and $\Omega_{s}$ to get a two-mode approximation:

$$
\omega(x, y, t, p) \approx \Omega_{s}(p) o_{s}(x, y, t)+\Omega_{d}(p) o_{d}(x, y, t),
$$

where $o_{s}$ and $o_{d}$ are the amplitudes of shallow and deep modes, respectively.

Multiple linear regression analysis is performed on the radiative flux convergence $R$ and the mode amplitudes:

$$
R(x, y, t) \cong R_{0}+r_{s} o_{s}(x, y, t)+r_{d} o_{d}(x, y, t),
$$

where $R_{0}$ is corresponding to spatially average radiative heating and $r_{s}$ and $r_{d}$ are corresponding to spatially varying interaction between radiation and clouds. We define the effective stabilities as $M_{\text {ses }}=(1 / g) \int_{p_{t}}^{p_{s}} \Omega_{s} \partial s / \partial p d p-r_{s}$ and $M_{\text {sed }}=(1 / g) \int_{p_{t}}^{p_{s}} \Omega_{d} \partial s / \partial p d p-r_{d}$ so that we can combine the Eq. (A1) with Eqs. (A2) and (A3):

$$
L P(x, y, t) \cong M_{\mathrm{ses}} o_{s}(x, y, t)+M_{\mathrm{sed}} o_{d}(x, y, t)-R_{0} .
$$

Next, we relate the $o_{s}$ to $\mathrm{SC}$ and $o_{d}$ to $\mathrm{SC}$ and relative SST $\left(\mathrm{SST}_{\text {rel }}\right)$, which is calculated as the difference between the SST and its average over the tropical oceans. By using the continuity equation at the surface, the shallow-mode amplitude $o_{s}$ is related to SC:

$$
\begin{aligned}
\operatorname{SC}(x, y, t)=\left(\frac{\partial \omega}{\partial p}\right)_{\text {surface }} & =\left(\frac{d \Omega_{s}}{d p}\right)_{\text {surface }} o_{s}(x, y, t), \\
o_{s}(x, y, t) & =a_{s} \operatorname{SC}(x, y, t),
\end{aligned}
$$

where the $a_{s}$ is given by $a_{s}=\left(\partial \Omega_{s} / \partial p\right)_{\text {surface }}^{-1}$, the evaluation of which is based on the two lowest pressure levels. To relate the deep-mode amplitude $o_{d}$ to SC and $\mathrm{SST}_{\text {rel }}$, the multiple linear regression analysis is performed:

$$
o_{d}(x, y, t) \cong b_{\mathrm{SST}} \operatorname{SST}_{\mathrm{rel}}(x, y, t)+b_{\mathrm{SC}} \mathrm{SC}(x, y, t)+b_{0} .
$$

Finally, we combine Eq. (A4) with Eqs. (A6) and (A7) to get a final model for tropical rainfall over oceans: 


$$
\begin{aligned}
L P_{\mathrm{TMM}} \cong & H(\chi) \chi, \\
\chi(x, y, t)= & M_{\mathrm{ses}} a_{s} \mathrm{SC}(x, y, t)+M_{\mathrm{sed}}\left[b_{\mathrm{SST}} \mathrm{SST}_{\mathrm{rel}}(x, y, t)\right. \\
& \left.+b_{\mathrm{SC}} \mathrm{SC}(x, y, t)+b_{0}\right]-R_{0},
\end{aligned}
$$

where $H(\chi)$ is the Heaviside function to avoid negative rainfall given by the model. The parameters $M_{\mathrm{ses}}, a_{s}$, $M_{\text {sed }}, b_{\mathrm{SST}}, b_{\mathrm{SC}}, b_{0}$, and $R_{0}$ are constants. In this study, we recombine the two-mode model rainfall $P_{\mathrm{TMM}}$ into two components: the terms related to SC are grouped together and named the SC component $P_{\mathrm{SC}}$ and other terms are grouped together and named heating component $P_{\text {Heat }}$ :

$$
\begin{aligned}
L P_{\mathrm{SC}} & =\left(M_{\text {ses }} a_{s}+M_{\text {sed }} b_{\mathrm{SC}}\right) \mathrm{SC}(x, y, t), \\
L P_{\text {Heat }} & =M_{\text {sed }} b_{\mathrm{SST}} \operatorname{SST}_{\text {rel }}(x, y, t)+M_{\text {sed }} b_{0}-R_{0} .
\end{aligned}
$$

\section{REFERENCES}

Adam, O., T. Schneider, and F. Brient, 2018: Regional and seasonal variations of the double-ITCZ bias in CMIP5 models. Climate Dyn., 51, 101-117, https://doi.org/10.1007/s00382-017-3909-1.

Adler, R. F., and Coauthors, 2003: The Version-2 Global Precipitation Climatology Project (GPCP) monthly precipitation analysis (1979-present). J. Hydrometeor., 4, 1147-1167, https://doi.org/ 10.1175/1525-7541(2003)004<1147:TVGPCP > 2.0.CO;2.

Back, L. E., and C. S. Bretherton, 2009a: On the relationship between SST gradients, boundary layer winds, and convergence over the tropical oceans. J. Climate, 22, 4182-4196, https:// doi.org/10.1175/2009JCLI2392.1.

- and _ 2009b: A simple model of climatological rainfall and vertical motion patterns over the tropical oceans. J. Climate, 22, 6477-6497, https://doi.org/10.1175/2009JCLI2393.1.

Bellucci, A., S. Gualdi, and A. Navarra, 2010: The double-ITCZ syndrome in coupled general circulation models: The role of largescale vertical circulation regimes. J. Climate, 23, 1127-1145, https://doi.org/10.1175/2009JCLI3002.1.

Bjerknes, J., 1969: Atmospheric teleconnections from the equatorial Pacific. Mon. Wea. Rev., 97, 163-172, https://doi.org/ 10.1175/1520-0493(1969)097<0163:ATFTEP>2.3.CO;2.

Dai, A., 2006: Precipitation characteristics in eighteen coupled climate models. J. Climate, 19, 4605-4630, https://doi.org/ 10.1175/JCLI3884.1.

Dee, D. P., and Coauthors, 2011: The ERA-Interim reanalysis: Configuration and performance of the data assimilation system. Quart. J. Roy. Meteor. Soc., 137, 553-597, https://doi.org/ 10.1002/qj.828

Duffy, M. L., P. A. O'Gorman, and L. E. Back, 2020: Importance of Laplacian of low-level warming for the response of precipitation to climate change over tropical oceans. J. Climate, 33, 4403-4417, https://doi.org/10.1175/JCLI-D-19-0365.1.

Eyring, V., S. Bony, G. A. Meehl, C. A. Senior, B. Stevens, R. J. Stouffer, and K. E. Taylor, 2016: Overview of the Coupled Model Intercomparison Project phase 6 (CMIP6) experimental design and organization. Geosci. Model Dev., 9, 1937-1958, https://doi.org/10.5194/gmd-9-1937-2016.
Fu, R., A. D. Del Genio, and W. B. Rossow, 1994: Influence of ocean surface conditions on atmospheric vertical thermodynamic structure and deep convection. J. Climate, 7, 1092-1108, https:// doi.org/10.1175/1520-0442(1994)007<1092:IOOSCO > 2.0.CO;2.

Fushan, D., Y. Rucong, Z. Xuehong, Y. Yongqiang, and L. Jianglong, 2005: Impacts of an improved low-level cloud scheme on the eastern Pacific ITCZ-cold tongue complex. Adv. Atmos. Sci., 22, 559-574, https://doi.org/10.1007/BF02918488.

Gill, A. E., and E. M. Rasmusson, 1983: The 1982-83 climate anomaly in the equatorial Pacific. Nature, 306, 229-234, https://doi.org/10.1038/306229a0.

Graham, N. E., and T. P. Barnett, 1987: Sea surface temperature, surface wind divergence, and convection over tropical oceans. Science, 238, 657-659, https://doi.org/10.1126/ science.238.4827.657.

Hall, A., P. Cox, C. Huntingford, and S. Klein, 2019: Progressing emergent constraints on future climate change. Nat. Climate Change, 9, 269-278, https://doi.org/10.1038/s41558-019-0436-6.

Hirota, N., Y. N. Takayabu, M. Watanabe, and M. Kimoto, 2011: Precipitation reproducibility over tropical oceans and its relationship to the double ITCZ problem in CMIP3 and MIROC5 climate models. J. Climate, 24, 4859-4873, https:// doi.org/10.1175/2011JCLI4156.1.

Huang, P., and J. Ying, 2015: A multimodel ensemble pattern regression method to correct the tropical Pacific SST change patterns under global warming. J. Climate, 28, 4706-4723, https://doi.org/10.1175/JCLI-D-14-00833.1.

Hwang, Y. T., and D. M. Frierson, 2013: Link between the doubleintertropical convergence zone problem and cloud biases over the Southern Ocean. Proc. Natl. Acad. Sci. USA, 110, 4935-4940, https://doi.org/10.1073/pnas.1213302110.

Li, G., and S.-P. Xie, 2012: Origins of tropical-wide SST biases in CMIP multi-model ensembles. Geophys. Res. Lett., 39, L22703, https://doi.org/10.1029/2012GL053777.

, - - and Y. Du, 2016: A robust but spurious pattern of climate change in model projections over the tropical Indian Ocean. J. Climate, 29, 5589-5608, https://doi.org/10.1175/ JCLI-D-15-0565.1.

Li, J., X. Zhang, Y. Yu, and F. Dai, 2004: Primary reasoning behind the double ITCZ phenomenon in a coupled ocean-atmosphere general circulation model. Adv. Atmos. Sci., 21, 857-867, https:// doi.org/10.1007/BF02915588.

Liebmann, B., and D. L. Hartmann, 1982: Interannual variations of outgoing IR associated with tropical circulation changes during 1974-78. J. Atmos. Sci., 39, 1153-1162, https://doi.org/ 10.1175/1520-0469(1982)039<1153:IVOOIA > 2.0.CO;2.

Lin, J.-L., 2007: The double-ITCZ problem in IPCC AR4 coupled GCMs: Ocean-atmosphere feedback analysis. J. Climate, 20, 4497-4525, https://doi.org/10.1175/JCLI4272.1.

Lindzen, R. S., and S. Nigam, 1987: On the role of sea surface temperature gradients in forcing low-level winds and convergence in the tropics. J. Atmos. Sci., 44, 2418-2436, https://doi.org/ 10.1175/1520-0469(1987)044<2418:OTROSS > 2.0.CO;2.

Liu, T. W., X. Xie, P. S. Polito, S.-P. Xie, and H. Hashizume, 2000: Atmospheric manifestation of tropical instability wave observed by QuikSCAT and tropical rain measuring mission. Geophys. Res. Lett., 27, 2545-2548, https://doi.org/10.1029/2000GL011545.

Mechoso, C. R., and Coauthors, 1995: The seasonal cycle over the tropical Pacific in coupled ocean-atmosphere general circulation models. Mon. Wea. Rev., 123, 2825-2838, https://doi.org/ 10.1175/1520-0493(1995)123<2825:TSCOTT >2.0.CO;2.

Möbis, B., and B. Stevens, 2012: Factors controlling the position of the intertropical convergence zone on an aquaplanet. J. $A d v$. 
Model. Earth Syst., 4, M00A04, https://doi.org/10.1029/ 2012MS000199.

Oueslati, B., and G. Bellon, 2013: Convective entrainment and large-scale organization of tropical precipitation: Sensitivity of the CNRM-CM5 hierarchy of models. J. Climate, 26, 29312946, https://doi.org/10.1175/JCLI-D-12-00314.1.

Ramage, C. S., 1977: Sea surface temperature and local weather. Mon. Wea. Rev., 105, 540-544, https://doi.org/10.1175/1520-0493(1977) $105<0540:$ SSTALW $>2.0$. CO;2.

Reynolds, R. W., N. A. Rayner, T. M. Smith, D. C. Stokes, and W. Wang, 2002: An improved in situ and satellite SST analysis for climate. J. Climate, 15, 1609-1625, https://doi.org/10.1175/ 1520-0442(2002)015<1609:AIISAS > 2.0.CO;2.

Samanta, D., K. B. Karnauskas, and N. F. Goodkin, 2019: Tropical Pacific SST and ITCZ biases in climate models: Double trouble for future rainfall projections? Geophys. Res. Lett., 46, 2242-2252, https://doi.org/10.1029/2018GL081363.

Sobel, A. H., J. Nilsson, and L. M. Polvani, 2001: The weak temperature gradient approximation and balanced tropical moisture waves. J. Atmos. Sci., 58, 3650-3665, https://doi.org/ 10.1175/1520-0469(2001)058<3650:TWTGAA > 2.0.CO;2.

Song, F., and G. J. Zhang, 2016: Effects of southeastern Pacific sea surface temperature on the double-ITCZ bias in NCAR CESM1. J. Climate, 29, 7417-7433, https://doi.org/10.1175/ JCLI-D-15-0852.1.

Song, X., and G. J. Zhang, 2009: Convection parameterization, tropical Pacific double ITCZ, and upper-ocean biases in the ncar CCSM3. Part I: Climatology and atmospheric feedback. J. Climate, 22, 4299-4315, https://doi.org/10.1175/2009JCLI2642.1.

, and - 2018: The roles of convection parameterization in the formation of double ITCZ syndrome in the NCAR CESM: I. Atmospheric processes. J. Adv. Model. Earth Syst., 10, 842-866, https://doi.org/10.1002/2017MS001191.

Stevens, B., J. Duan, J. C. McWilliams, M. Münnich, and J. D. Neelin, 2002: Entrainment, Rayleigh friction, and boundary layer winds over the tropical Pacific. J. Climate, 15, 30-44, https://doi.org/ 10.1175/1520-0442(2002)015<0030:ERFABL >2.0.CO;2.

Taylor, K. E., R. J. Stouffer, and G. A. Meehl, 2012: An overview of CMIP5 and the experiment design. Bull. Amer. Meteor. Soc., 93, 485-498, https://doi.org/10.1175/BAMS-D-11-00094.1.

Tian, B., 2015: Spread of model climate sensitivity linked to double-intertropical convergence zone bias. Geophys. Res. Lett., 42, 4133-4141, https://doi.org/10.1002/2015GL064119.
Wittenberg, A. T., A. Rosati, N.-C. Lau, and J. J. Ploshay, 2006: GFDL'S CM2 global coupled climate models. Part III: Tropical Pacific climate and ENSO. J. Climate, 19, 698-722, https://doi.org/10.1175/JCLI3631.1.

Woelfle, M. D., C. S. Bretherton, C. Hannay, and R. Neale, 2019: Evolution of the double-ITCZ bias through CESM2 development. J. Adv. Model. Earth Syst., 11, 1873-1893, https:// doi.org/10.1029/2019MS001647.

Xie, S.-P., C. Deser, G. A. Vecchi, J. Ma, H. Teng, and A. T. Wittenberg, 2010: Global warming pattern formation: Sea surface temperature and rainfall. J. Climate, 23, 966-986, https://doi.org/10.1175/2009JCLI3329.1.

Ying, J., and P. Huang, 2016: Cloud-radiation feedback as a leading source of uncertainty in the tropical Pacific SST warming pattern in CMIP5 models. J. Climate, 29, 3867-3881, https://doi.org/10.1175/JCLI-D-15-0796.1.

Yu, J.-Y., and C. R. Mechoso, 1999: Links between annual variations of peruvian stratocumulus clouds and of SST in the eastern equatorial Pacific. J. Climate, 12, 3305-3318, https://doi.org/ 10.1175/1520-0442(1999)012<3305:LBAVOP > 2.0.CO;2.

Zhang, C., 1993: Large-scale variability of atmospheric deep convection in relation to sea surface temperature in the tropics. J. Climate, 6, 1898-1913, https://doi.org/10.1175/1520-0442(1993) 006<1898:LSVOAD > 2.0.CO;2.

Zhang, G. J., and X. Song, 2010: Convection parameterization, tropical Pacific double ITCZ, and upper-ocean biases in the NCAR CCSM3. Part II: Coupled feedback and the role of ocean heat transport. J. Climate, 23, 800-812, https://doi.org/ 10.1175/2009JCLI3109.1.

Zhang, L., C. Wang, Z. Song, and S.-K. Lee, 2014: Remote effect of the model cold bias in the tropical North Atlantic on the warm bias in the tropical southeastern Pacific. J. $A d v$. Model. Earth Syst., 6, 1016-1026, https://doi.org/10.1002/ 2014MS000338.

Zheng, Y., T. Shinoda, J.-L. Lin, and G. N. Kiladis, 2011: Sea surface temperature biases under the stratus cloud deck in the southeast Pacific Ocean in 19 IPCC AR4 coupled general circulation models. J. Climate, 24, 4139-4164, https://doi.org/ 10.1175/2011JCLI4172.1.

_ J.-L. Lin, and T. Shinoda, 2012: The equatorial Pacific cold tongue simulated by IPCC AR4 coupled GCMs: Upper ocean heat budget and feedback analysis. J. Geophys. Res., 117, C05024, https://doi.org/10.1029/2011JC007746. 